\title{
Acute obstructive pancreatitis caused by a migrated balloon gastrostomy tube
}

\author{
Mamatha Bhat MD, Eileen Bridges MD
}

$\mathrm{A}$ 25-year-old woman with a history of cerebral palsy, developmental disability and corpus callosotomy for tonicclonic seizures was brought to hospital with a two-day history of progressively worsening nausea and abdominal pain. She was being fed via a percutaneous endoscopic gastrostomy (PEG) tube that had been changed three days earlier at her nursing home and had become blocked. Because she could not receive her antiepileptic medication, tonic-clonic seizures developed, which were treated with intravenous anticonvulsants.

Physical examination showed a low-grade fever, epigastric tenderness and bilious fluid leaking from around the PEG tube. Blood tests showed a leukocyte count of 17.8 (normal 4.3$10.8) \times 10^{9} / \mathrm{L}$, an amylase level of 2941 (normal 40-140) IU/L, a lipase level of 675 (normal 10150 ) IU/L and a bilirubin level of 22 (normal 320) $\mu \mathrm{mol} / \mathrm{L}$. Liver enzyme levels, including alkaline phosphatase and alanine aminotransferase, were normal. Abdominal computed tomography identified the PEG balloon in the second stage of her duodenum, compressing the pancreatic head and the terminal portion of the common bile duct with resultant obstructive pancreatitis (Figure 1).

The PEG tube was replaced and the external bolster was carefully tightened to prevent migration. Placement was confirmed with a Gastrografin study, and the patient's pancreatitis resolved.

Insertion of a PEG tube is generally a safe procedure, although pancreatitis is a rare complication..$^{1-3}$ Symptoms such as abdominal pain, recurrent vomiting, increased leakage around the stoma and jaundice should raise clinical suspicion of pancreatitis and gastrointestinal obstruction from a migrated PEG tube. Physicians replacing PEG tubes should ensure that the external bolster is no more than 1 to $2 \mathrm{~cm}$ away from the abdominal wall, such that the internal bolster (a balloon in replacement PEGs) is

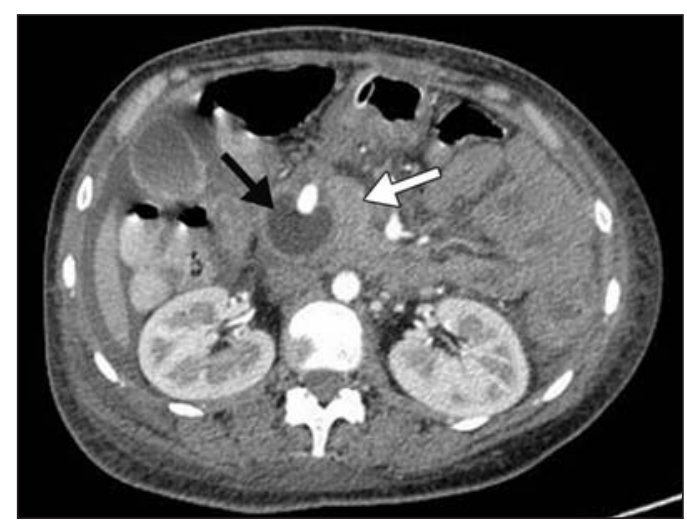

Figure 1: Abdominal computed tomographic scan of a 25-year-old woman with abdominal pain, three days after her balloon gastrostomy tube was changed. The pancreas is slightly enlarged with peripancreatic fluid (white arrow). The tube is in the second portion of the duodenum (black arrow).

apposed to the anterior gastric wall and migration is prevented (Appendix 1, available at www.cmaj.ca/lookup/suppl/doi:10.1503/cmaj $.101198 /-/ D C 1)$. Overtightening the external bolster can lead to cutaneous ulceration or a "buried bumper syndrome" caused by the internal bolster digging into the anterior gastric wall. Expert guidelines recommend a Gastrografin study after blind placement of the gastrostomy tube. ${ }^{4}$ The feeding tube should be marked where it exits from the abdominal wall once adequate placement has been documented. ${ }^{4}$

\section{References}

1. Duerksen DR. Acute pancreatitis caused by a prolapsing gastrostomy tube. Gastrointest Endosc 2001;54:792-3.

2. Imamura $\mathrm{H}$, Konagaya $\mathrm{T}$, Hashimoto $\mathrm{T}$, et al. Acute pancreatitis and cholangitis: a complication caused by a migrated gastrostomy tube. World J Gastroenterol 2007;13:5285-7.

3. Miele VJ, Nigam A. Obstructive jaundice and pancreatitis secondary to percutaneous endoscopic gastrostomy tube migration. J Gastroenterol Hepatol 2005;20:1802-3.

4. Bankhead R, Boullatta J, Brantley S, et al. Enteral nutrition practice recommendations. J Parenter Enteral Nutr 2009;33. $122-67$.
Competing interests: None declared.

This article has been peer reviewed.

Affiliations:

From the Divisions of Gastroenterology (Bhat) and Emergency Medicine (Bridges), McGill University Health Centre, Montréal, Que.

Correspondence to: Dr. Mamatha Bhat, mamatha.bhat@mail .mcgill.ca

CMAJ 2011. DOI:10.1503 /cmaj.101198 